\title{
Measurement of Quality of Educational Hospital Services by the SERVQUAL Model: The Iranian Patients' Perspective
}

\author{
Satar Rezaei ${ }^{1}$, Behzad Karami Matin ${ }^{2}$, Khalil Moradi ${ }^{3}$, Behroz Bijan ${ }^{3}$, Masoud Fallahi ${ }^{3}$, Behnam Shokati ${ }^{4}$, Hamid \\ Saeidi $^{5}$
}

${ }^{1}$ Ph.D. Candidate in Health Economics, Research Center for Environmental Determinants of Health, Kermanshah University of Medical Sciences, Kermanshah, Iran

${ }^{2}$ Ph.D. of Health Services Management, Associate Professor, Research Center for Environmental Determinants of Health, Kermanshah University of Medical Sciences, Kermanshah, Iran

${ }^{3}$ M.Sc. of Nursing, Imam Reza Hospital, Kermanshah University of Medical Sciences, Kermanshah, Iran

${ }^{4}$ B.Sc. of Nursing, School of Nursing, Aja University of Medical Sciences Student Research Committee, Tehran, Iran

${ }^{5}$ M.Sc. of Nursing, Student Research Committee, Tabriz University of Medical Sciences, Tabriz, Iran

Type of article: Original

\begin{abstract}
Introduction: The main mission of hospitals in any health system is to deliver high quality healthcare for patients and meet their needs and expectations. The aim of the current study was to assess the quality of the service of educational hospitals affiliated with Kermanshah University of Medical Sciences in 2015, from the perspective of patients.

Methods: In this cross-sectional study, the perspectives of 400 patients were assessed about the quality of the services provided by educational hospitals in Kermanshah (western Iran) in 2015. The quality was assessed by the SERVQUAL questionnaire with five dimensions, i.e., tangibility, reliability, responsiveness, assurance, and empathy. In addition, the Wilcoxon test and the Kruskal-Wallis test were used to explore any association between the dependent variable and explanatory variables. The data were analyzed using Stata V.12 software.

Results: There were negative gaps in all five dimensions. The highest and lowest gaps in the mean score were found in the assurance $(-0.88)$ and responsiveness $(-0.56)$ dimensions. The patients ranked responsiveness as the most important dimension of the quality of healthcare.

Conclusion: There were gaps between the patients' perceptions and their expectation about the five dimensions that were studied based on the SERVQUAL model. Also, it is recommended that improving the quality of healthcare is possible by various policies, such as good responsiveness, access to health workers, and delivering healthcare in less time.
\end{abstract}

Keywords: quality of healthcare, patient's perception, patient's expectation, SERVQUAL

\section{Introduction}

Quality of services is one of the most important factors for growth, success, and the presences of organizations, and it was considered as an effective and comprehensive strategy in order to improve their performances throughout the world $(1,2)$. In the health sector compared with other sectors, the quality of health services provided is more than important because the health sector has a significant association with the length of people's lives and their wellbeing. Because of the importance of health services, the quality of health services provided by health organizations is becoming more and more crucial, and the demands for quality control, management, and improvements are increasing $(3,4)$. Hospitals, as the main providers of healthcare services in all countries, should be moved toward its main objectives, including providing healthcare services with high quality and meeting the needs and expectations

\section{Corresponding author:}

Khalil Moradi, Imam Reza Hospital, Kermanshah University of Medical Sciences, Kermanshah, Iran.

Tel: +98.8338262229, Fax: +98. 8338262229, Email: Moradi.khalil12@gmail.com

Received: November 14, 2015, Accepted: February 20, 2016, Published: March 2016

iThenticate screening: February 20, 2016, English editing: February 28, 2016, Quality control: March 08, 2016

(C) 2016 The Authors. This is an open access article under the terms of the Creative Commons Attribution-NonCommercialNoDerivs License, which permits use and distribution in any medium, provided the original work is properly cited, the use is non-commercial and no modifications or adaptations are made. 
of patients $(4,5)$. The main ways to improve the quality of healthcare services is to monitor and evaluate the quality of the healthcare provided over time by using valid tools and models for the measurement of quality. One of the best and most extensively used models for evaluating of the quality of the healthcare services is the SERVQUAL (service quality) model, which was introduced by Parasuraman et al. in 1980 (6-8). This model also is recognized as the gap analyzer model, and it measure the gap between the expectations and perceptions of the patients regarding the quality of services provided by hospitals. However, in this model, the quality of healthcare services is defined as the difference between performance (what is) and expectations (what should be) $(4,7,9)$. Some researchers used the SERVQUAL model to measure the quality of healthcare services in various countries (6, 7, 10-16). Mustafa et al. showed that, in hospitals in Egypt, patients' expectations concerning the quality of the healthcare services were affected on their stratification from types of services and hospitals (public or private) (18). A study by Miranda and et al. on 644 patients injured by vehicle accidents in Peru in 2013 indicated that $95 \%$ of patients in public hospitals and $78 \%$ of patients in private hospitals were dissatisfied with the quality of the healthcare services provided by these hospitals (19). Tabibi et al. showed that there are significant differences between patients' expectations and their perception of the actual quality of healthcare. They also concluded that patients ranked the assurance and responsiveness domains as the most and least important, respectively (20). According to the importance of measuring quality in the health sector and its role in health promotion, this study aimed to determine the different dimensions of the quality of the services being provided in educational hospitals in western Iran and to evaluate the quality of the hospitals' services from the patients' perspectives.

\section{Material and Methods}

\subsection{Study design and setting}

This cross-sectional study was conducted during the summer of 2015 in educational hospitals in Kermanshah in western Iran. The research population of this study included patients who were hospitalized at least two days in seven educational hospitals, i.e., Farabi, Taleqani, Imam Reza, Imam Khomeini, Mohammad Kermanshahi, Imam Ali, and Moetazedi Hospitals.

\subsection{Sampling}

The sample size for the study was determined to be 400 patients. The patients were divided among the seven hospitals based on proportionality to the size. The patients were selected randomly in each hospital, and the questionnaires were given to them on the day they were discharged.

\subsection{Survey instrument}

The SERVQUAL questionnaire was used to collect the required data. This questionnaire consists of two parts. The first part includes 7 questions regarding the socio-demographic information of the patients, and the second part includes 22 items in 5 service quality dimensions, i.e., tangibility (4 items), reliability (4 items), responsiveness (4 items), assurance (5 items), and empathy (5 items). The reliability and validity of the questionnaire were confirmed by previous studies $(10,12)$, and the Persian version was available. A five-point Likert scale, varying from strongly disagree (1) to strongly agree (5), was used to measure the expectations and perceptions of then patients about level of service quality.

\subsection{Data analysis}

The quality gap was computed as the difference between the expectation and perception scores. We asked the patients to rank the five dimensions of service quality according to the importance of the dimension. The significance of the difference between the mean score of the patients' expectations and their perceptions was checked by the Wilcoxon test. The Kruskal-Wallis test was used to compare the mean score of the patients' expectations and their perceptions in different socio-demographic levels. A p-value less than 0.05 was considered to be statistically significant. The data analysis was done by Stata V.12.

\subsection{Research ethics}

This study was approved by the Ethics Committee of the Deputy of Research, Kermanshah University of Medical Sciences. The first and last names of the patients, the name of the hospital, the name of the physician, the name of the ward in which the patients were hospitalized, and the number of international code were considered confidential to ensure the ethics of this research. 


\section{Results}

Four hundred patients were included in the study of which $63 \%$ (252) were males and $37 \%(148)$ were females. The results showed the average age of the respondents was 38.5 years with a standard deviation of 23.6. (The ages varied from 1 to 89 .) In addition, $6.6 \%$ of the patients were illiterate; $94.4 \%$ of the patients had insurance coverage. The average length of stay was 4.5 days $(\mathrm{SD}=3.8)$. The descriptive characteristics of the study population are shown in Table 1. Table 2 presents the mean scores of the patients' expectations, their perceptions, and quality gap in the five dimensions of service quality based on the SERVQUAL model. Based on our findings, the overall mean scores of their perceptions and their expectations of service quality were 3.81 and 4.58 , respectively.

Table1. Socio-demographic characteristics of the study population, Kermanshah, western Iran, 2014

\begin{tabular}{|c|c|c|c|}
\hline \multicolumn{2}{|l|}{ Variables } & $\mathrm{n}$ & $\%$ \\
\hline \multirow[t]{2}{*}{ Gender } & Male & 252 & 63 \\
\hline & Female & 148 & 37 \\
\hline \multirow[t]{5}{*}{ Age (year) } & $<15$ & 40 & 10 \\
\hline & $16-30$ & 74 & 18.5 \\
\hline & $31-45$ & 88 & 22 \\
\hline & $46-60$ & 85 & 21.3 \\
\hline & $>61$ & 112 & 28.2 \\
\hline \multirow[t]{3}{*}{ Level of education } & Illiterate & 26 & 6.6 \\
\hline & Primary and secondary school & 290 & 72.4 \\
\hline & Academic degree & 84 & 21 \\
\hline \multirow[t]{2}{*}{ Geolocality } & Urban & 290 & 72.5 \\
\hline & Rural & 110 & 27.5 \\
\hline \multirow[t]{2}{*}{ Insurance coverage } & Yes & 377 & 94.4 \\
\hline & No & 23 & 5.6 \\
\hline \multirow[t]{3}{*}{ Marital status } & Single & 103 & 25.7 \\
\hline & Married & 277 & 69.3 \\
\hline & Others & 20 & 5 \\
\hline \multirow[t]{3}{*}{ Length of stay (LOS) } & 3-5 days & 283 & 70.8 \\
\hline & 6-14 days & 85 & 21.2 \\
\hline & $>15$ days & 32 & 8 \\
\hline
\end{tabular}

Table 2. Mean scores of expectation, perception of the patients and quality gap of services provided by educational hospitals in Kermanshah, 2015

\begin{tabular}{|l|l|l|l|l|}
\hline \multirow{2}{*}{ Dimensions } & \multicolumn{2}{|l|}{ Mean scores } & \multirow{2}{*}{-value } \\
\cline { 2 - 5 } & Perception & Expectation & Gap & \\
\hline Tangibility & $3.81 \pm 1.12$ & $4.61 \pm 0.9$ & -0.8 & $<0.001$ \\
\hline Reliability & $3.65 \pm 1.21$ & $4.43 \pm 0.8$ & -0.78 & $<0.001$ \\
\hline Responsiveness & $3.96 \pm 1.45$ & $4.52 \pm 0.51$ & -0.56 & $<0.001$ \\
\hline Assurance & $3.82 \pm 1.33$ & $4.70 \pm 0.65$ & -0.88 & $<0.001$ \\
\hline Empathy & $3.78 \pm 1.6$ & $4.65 \pm 0.34$ & -0.87 & $<0.001$ \\
\hline Total quality & $3.8 \pm 1.06$ & $4.58 \pm 0.59$ & -0.78 & $<0.001$ \\
\hline
\end{tabular}

Also, the score gap between overall mean score of perceptions and expectations was -0.78 , and this gap was statistically significant. The study showed that the highest and lowest perception score was related to the responsiveness (3.96) and reliability (3.65), respectively. Also, the highest and lowest expectation score was related to the assurance (4.7) and reliability (4.43), respectively. Our empirical analysis indicated that there was a statistically significant difference between the mean score of perception and their expectation of the patients in all dimensions. However, there was a gap between perception and expectation of the service quality of educational hospital in Kermanshah in western Iran (Table 2). The status of quality gap in all of the dimensions between expectations and perceptions of the patients about service quality is shown in Figure 1. Based on this figure, the highest quality gap was related to assurance $(-0.88)$, whereas the lowest quality gap was associated with responsiveness (-0.56). Our findings about the important five dimensions from the patients' perspectives are shown in Figure 2. The majority of patients (more than $80 \%$ ) rated all of the dimensions of service quality as important and 
very important, i.e., responsiveness (91\%), tangibility (75\%), reliability (86\%), assurance (79\%), and empathy $(83 \%)$ (Figure 2$)$. The results of Kruskal-Wallis test indicated that there was no association between the mean score of expectation of the patients and their perception in different age ( $p$-value $=0.76)$, gender $(p$-value $=0.31)$, education level $(p$-value $=0.064)$, and marital status $(p$-value $=0.092)$.

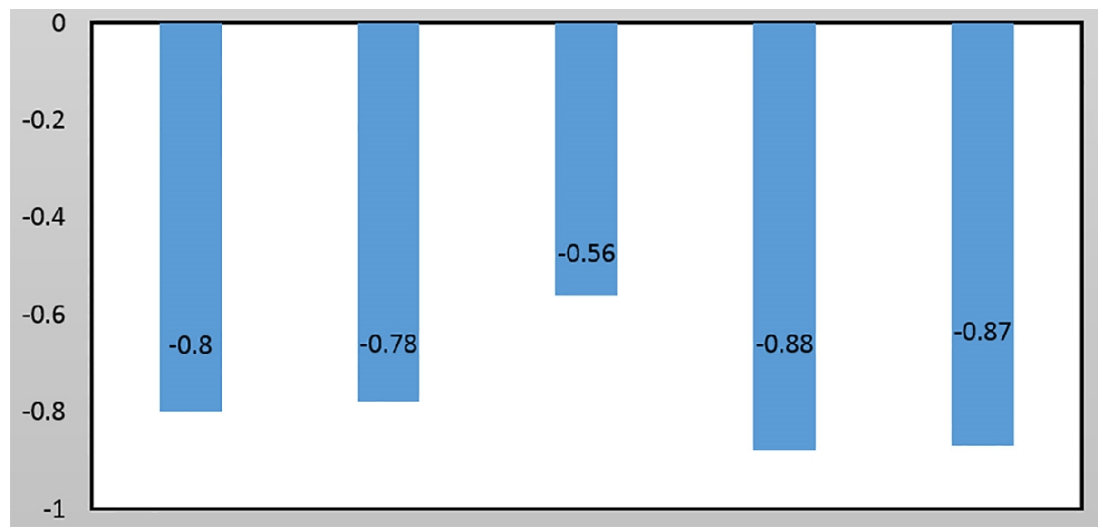

Figure 1. Status of quality gap in all of dimension based on SERVQUAL model in Kermanshah, 2015

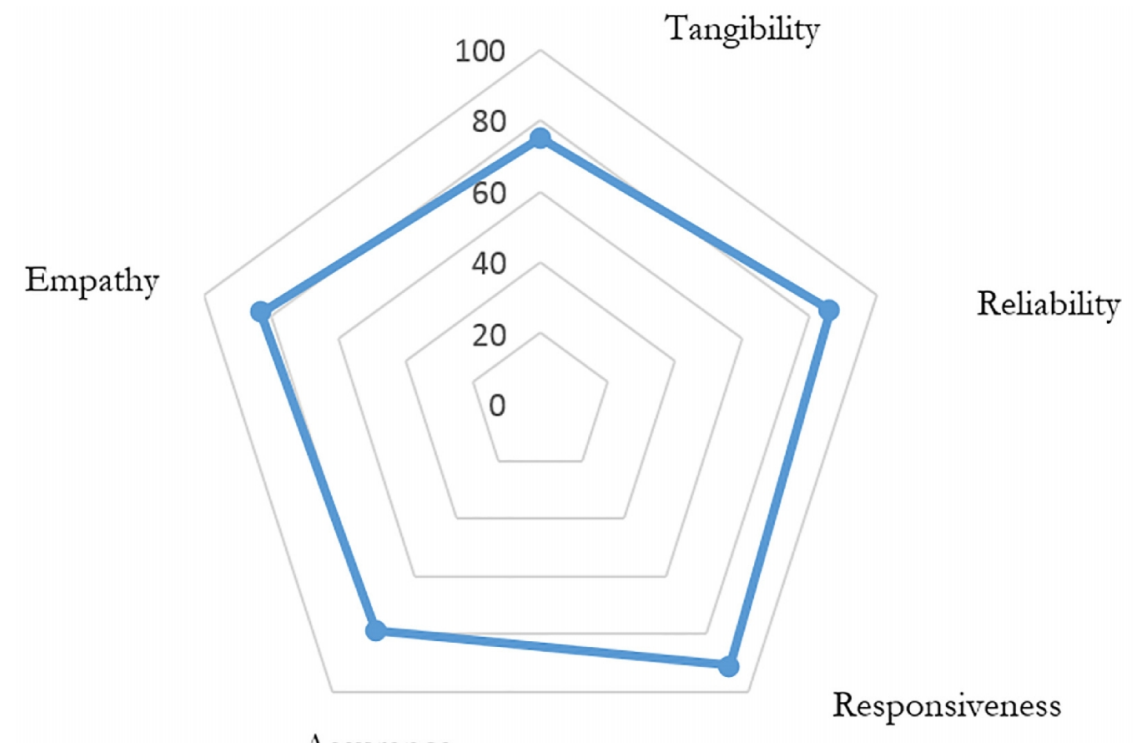

Assurance

Figure 2. Percentage of patients rated quality domains as important or very important

\section{Discussion}

The main objective of the study was to measure the gap of the service quality provided based on expectation of patients and their perception in educational hospitals in Kermanshah in western Iran in 2015. Furthermore, to help health policy-makers and hospital managers in suitable programming to allocate financial resources for improving performance that have affected the perceptions of the patients of service quality $(10,21)$. Based on the results of our study, there are negative gaps in all of dimensions concerning the quality of services provided by the hospitals. The results also indicated that there are significant difference between perception and expectation of patients of the service quality provided. This result is similar with the study conducted by Tabibi et al. in hospitals in Tehran, Iran, in 2011 (7), the study by Anbari and Tabaraie in Arak, Iran, in 2012 (22), the study by Brahmbhatt et al. in hospitals in India in 2011 (23), the study of Lim and Tang in Singapore hospitals in 2000 (24), and the study of Huseyin et al. in hospitals in Greece (21). The study showed that the highest and lowest mean score of perception were related to responsiveness and reliability, respectively, whereas the highest and lowest mean score of expectation were associated with assurance and reliability, respectively. This result was consistent with the results of studies conducted by Aghamolaei and et al. (25), Lim and Tang in Singapore hospitals (24), and Karydis et al. in dental 
healthcare in Greece (26). In a study by Aghamolaei et al. in Shahid Mohammadi hospital in Bandar Abbas in Hormozgan Province in southern Iran, it was reported that the highest expectation was related to the assurance dimension (25). As the results showed, assurance had the highest negative gap among all of the dimensions, whereas the lowest negative gap was related to responsiveness. These results paralleled the results of previous studies $(7,27$, 28). Bahadori et al. in the Armed Forces Hospital of Hamadan reported the responsiveness (-0.22) and assurance (0.43 ) had the highest and the lowest gap of quality in all of dimensions, respectively (7). Also, in a study conducted by Havasbigi el al. in public hospitals in Kermanshah and Ilam, western Iran, the highest and lowest negative gap in all of dimension based on SERVQUAL model was found to be assurance (-1.36) and tangibility (-0.87), respectively (28). The current study also had several limitations. First, the study conducted in the educational hospitals in Kermanshah City in western Iran and other studies must be piloted in other hospitals, such as private hospitals and social security hospitals to increase the generalizability of the results of the study. Another limitation was that the majority of the patients lived in urban areas and had insurance coverage. Thus, based on the limitations of the study, our findings must be used with caution, and generalization of the results was restricted to the actual population of

Kermanshah Province, especially people who live in the rural areas without insurance coverage and the hospitals of other towns in Kermanshah Province.

\section{Conclusions}

The current study indicated that there were negative gaps in all of the dimensions in the studied hospitals. However, the expectations of the patients concerning the quality of the services provided were higher than their perceptions of the quality of those services. Based on our study, it is suggested that the planners and managers of hospitals must improve the timeliness of the delivery of care and enhance the communication skills of staff members in order to increase the quality of the services provided. The authors recommend that future studies be conducted in private and social security hospitals and that the results be compared to the results of this study.

\section{Acknowledgments:}

This article was extracted from an approved project with code number 3002741 at Kermanshah University of Medical Sciences and was funded and supported by the Research Deputy of Kermanshah University of Medical Sciences. Also, we thank Dr. Soofi from the Department of Health Management and Economics (School of Public Health, Tehran University of Medical Sciences) for improving our use of the English language in the manuscript. The authors appreciate all people who helped them in this project.

\section{Conflict of Interest:}

There is no conflict of interest to be declared.

\section{Authors' contributions:}

All authors contributed to this project and article equally. All authors read and approved the final manuscript.

\section{References}

1) Wong A, Sohal A. Service quality and customer loyalty perspectives on two levels of retail relationships. J Serv Market. 2003; 17(5): 495-513. doi: 10.1108/08876040310486285.

2) Sahney S, Banwet D, Karunes S. An integrated framework for quality in education: Application of quality function deployment, interpretive structural modelling and path analysis. Total Qual Manag Bus Excel. 2006; 17(2): 265-85. doi: 10.1080/14783360500450376.

3) Sahney S, Banwet DK, Karunes S. An integrated framework for quality management in education: a faculty perspective. TQM J. 2008; 20(5): 502-19. doi: 10.1108/17542730810898467.

4) Sabahi-Bidgoli M, Mousavi SGA, Kebriaei A, Seyyedi SH, Shahri S, Atharizadeh M. The quality of hospital services in Kashan educational hospitals during 2008-9: the patients' viewpoint. Feyz Journals of Kashan University of Medical Sciences. 2011; 15(2): 146-52.

5) Ranjbar Ezzatabadi M, Bahrami MA, Zare Ahmadabadi H, Nasiri S, Arab M, Hadizadeh F, et al. Gap Analysis between Perceptions and Expectations of Service Recipients through Servqual Approach in Yazd, Afshar Hospital. Tolooe Behdasht. 2010; 9(2,3): 75-86.

6) Heidarnia MA, Abadi A, Mohseni M. Cross cultural adaptation and assessing validity and reliability of SERVQUAL questionnaire in hospital service quality. Research in Medicine. 2014; 38(2): 98-105.

7) Bahadori M, Zaboli R, Ghanbari A. Quality of services provided to veterans referred to a branch of the armed forces in Hamadan. Iranian Journal of War and Public Health. 2013; 6(1): 44-50.

8) Parasuraman A, Zeithaml VA, Berry LL. Servqual. Journal of retailing. 1988; 64(1): 12-40. 
9) Caruana A, Ewing MT, Ramaseshan B. Assessment of the three-column format SERVQUAL: an experimental approach. J Bus Res. 2000; 49(1): 57-65. doi: 10.1016/S0148-2963(98)00119-2.

10) Ajam M, Sadeghifar J, Anjomshoa M, Mahmoudi S, Honarvar H, Mousavi SM. Assessing quality of healthcare service by the SERVQUAL model: A case study of a field hospital. J Mil Med. 2014; 15(4): 273-9.

11) Gorji H, Tabatabaei S, Akbari A, Sarkhosh S, Khorasan S. Using the service quality gap's model (SERVQUAL) in Imam Khomeini teaching hospital: 2012. Journal of Health Administration (JHA). 2013; 16(51): 7-18.

12) Mohammadi A, Eftekhare-Ardabili H, Akbari-Hagigi F, Mahmudi M, Purreza A. Measurement quality of services based on expectations and perceptions of patients in the hospital of Zanjan. J School Health \& Health Res Inst. 2003; 2: 71-84.

13) Mohammadnia M, Delgoshaei B, Tofighi S, Riahi L, Omrani A. Survey on Nursing Service Quality by SERVQUAL at Tehran Social Security Organization Hospitals. Hospital. 2010; 8(3): 68-73.

14) Butt MM, de Run EC. Private healthcare quality: applying a SERVQUAL model. Int J Health Care Qual Assur. 2010; 23(7): 658-73. doi: 10.1108/09526861011071580, PMID: 21125961.

15) Ramanujam P. Service Quality in Health Care Organisations A Study of Corporate Hospitals in Hyderabad. Journal of Health Management. 2011; 13(2): 177-202. doi: 10.1177/097206341101300204

16) Al-Borie HM, Damanhouri AM. Patients' satisfaction of service quality in Saudi hospitals: a SERVQUAL analysis. Int J Health Care Qual Assur. 2013; 26(1): 20-30. PMID: 23534103, doi: 10.1108/09526861311288613.

17) Curry A, Sinclair E. Assessing the quality of physiotherapy services using SERVQUAL. Int J Health Care Qual Assur. 2002; 15(5): 197-205. doi: 10.1108/09526860210437412.

18) Mostafa MM. An empirical study of patients' expectations and satisfactions in Egyptian hospitals. Int J Health Care Qual Assur Inc Leadersh Health Serv. 2005; 18(7): 516-32. doi: 10.1108/09526860510627201, PMID: 16335615.

19) Miranda JJ, Rosales-Mayor E, Quistberg DA, Paca-Palao A, Gianella C, Perel P, et al. Patient perspectives on the promptness and quality of care of road traffic incident victims in Peru: a cross-sectional, active surveillance study. F1000Res. 2013; 9(2): 167-71. doi: 10.12688/f1000research.2-167.v1, PMID: 24358877.

20) Tabibi SJ, Gohari MR, Shahri S, Aghababa S. Assessment of Health Care Services in outpatient clinics based on SERVQUAL model in Hospitals of Tehran. Payavard Salamat. 2012; 5(4): 49-56.

21) Arasli H, Ekiz EH, Katircioglu ST. Gearing Service quality into Publice and Private hospitals in smallisland;Epirical Evidence from Cyprus. Int J Health Care Qual Assur. 2008; 21(1): 1-14. doi: 10.1108/09526860810841129, PMID: 18437935.

22) Anbari Z, TabaraieY. Measurement of Quality of Hospital Services via SERVQUAL Model. Bull Env Pharmacol Life Sci. 2013; 3(1): 51-6.

23) Brahmbhatt M, Baser N, Loshi N. Adapting the Servqual Scale to Hospital Services: An Empirical Investigation of Patients' Perceptions of Service Quality. International Journal of Multidisciplinary Research. 2011; 1(8): 27-42.

24) Lim PC, Tang NK. A study of patients' expectations and satisfaction in Singapore hospitals. Int J Health Care Qual Assur Inc Leadersh Health Serv. 2000; 13(6-7): 290-9. doi: 10.1108/09526860010378735, PMID: 11484647.

25) Aghamolaei T, Eftekhaari TE, Rafati S, Kahnouji K, Ahangari S, Shahrzad ME, et al. Service quality assessment of a referral hospital in Southern Iran with SERVQUAL technique: patients' perspective. BMC Health Serv Res. 2014; 14: 322. doi: 10.1186/1472-6963-14-322, PMID: 25064475, PMCID: PMC4115484.

26) Karydis A, Komboli M, Pannis V. Expectation and perception of Greek patients regarding the quality of dental health care. Int J Qual Health Care. 2001; 13(5): 409-16. PMID: 11669569.

27) Esteki R, Attafar A. Quality of nursing services (contemporary level of reality and level of expectation) from nurses' viewpoint on the basis of SERVQUAL Model in Al-Zahra Hospital in Isfahan (2010). Mod Care J. 2012; 9 (2): 72-9.

28) Havasbeigi F, Yasbalaghisharahi B, Mohamadi E, Mohamadi A. Measuring the Quality of Services Provided For Outpatients In Public Hospitals In Ilam and Kermanshah Cities Based on The SERVQUAL Instrument. Scientific Journal of Ilam University of Medical Sciences. 2013; 21(3): 207-14. 